\title{
Comparison of the therapeutic effects of surgery following prism adaptation test versus surgery alone in acute acquired comitant esotropia
}

\author{
Peng Zhang, Ying Zhang, Lei Gao and Jun Yang*
}

\begin{abstract}
Background: To compare the therapeutic effects of surgery following prism adaptation test versus surgery alone in acute acquired comitant esotropia (AACE).

Methods: A total of 46 patients with AACE were enrolled in this retrospective study. Among them, 26 patients underwent surgery following prism adaptation test (combination group) and 20 patients underwent surgery alone (surgery group). The following parameters were evaluated including success rate, distant and near deviation angles, visual function, and near stereoacuity.

Results: There were no significant differences in success rate between the combination group and surgery group at post-treatment 12 months ( $96.15 \%$ vs. $90.00 \%, p>0.05)$. The postoperative distant and near deviation angles in two groups were significantly lower than that before surgery $(p<0.05)$. In addition, the numbers of patients with stereopsis postoperatively in two groups were significantly higher than that before surgery (all $p<0.05)$. Moreover, the numbers of patients with stereopsis and central stereopsis in the combination group were significantly higher than that in the surgery group postoperatively. At post-treatment 12 months, one $(3.85 \%)$ case recurred in combination group and three (15.00\%) cases in the surgery group. No complications were observed in the two groups.
\end{abstract}

Conclusions: Both approaches had therapeutic benefit in AACE. Surgery following prism adaptation test had better treatment benefits than surgery alone in improving binocular function and reducing recurrence rate.

Keywords: Acute acquired comitant esotropia, Deviation angles, Prism adaptation test, Visual function

\section{Background}

Acute acquired comitant esotropia (AACE) is a rare type of esotropia that usually occurs in older children and adults [1]. It is classified into three types: 1) Swan type: esotropia due to monocular occlusion or loss of vision in one eye; 2) Burian-Franceschetti type: esotropia characterized by minimal hypermetropia and diplopia, often

\footnotetext{
* Correspondence: YJsherty1@126.com

Department of Ophthalmology, Jinan 2nd People's Hospital, No.148, Jingyi Road, Huaiyin District, Jinan 250001, China
}

associated with physical or psychological stress; 3) Bielschowsky type: esotropia in patients with varying degrees of myopia, and shows equal deviation at near and distance fixation [2,3]. Its clinical characteristics include an acute onset of comitant esotropia with diplopia (same deviation in all gaze direction), normal ocular motility, recessive, constant or intermittent esotropia, and a certain binocular visual function $[4,5]$. The current treatment strategies are surgery, botulinum toxin injection and prescription of prism glasses $[3,6,7]$. Botulinum

(c) The Author(s). 2020 Open Access This article is licensed under a Creative Commons Attribution 4.0 International License, which permits use, sharing, adaptation, distribution and reproduction in any medium or format, as long as you give appropriate credit to the original author(s) and the source, provide a link to the Creative Commons licence, and indicate if changes were made. The images or other third party material in this article are included in the article's Creative Commons licence, unless indicated otherwise in a credit line to the material. If material is not included in the article's Creative Commons licence and your intended use is not permitted by statutory regulation or exceeds the permitted use, you will need to obtain permission directly from the copyright holder. To view a copy of this licence, visit http://creativecommons.org/licenses/by/4.0/. The Creative Commons Public Domain Dedication waiver (http://creativecommons.org/publicdomain/zero/1.0/) applies to the data made available in this article, unless otherwise stated in a credit line to the data. 
toxin has been used to diagnose and treat different types of strabismus since the 1970s [8]. Compared with standard strabismus surgery, botulinum toxin injection has many advantages, such as simple operation, short anesthesia time, short post-anesthesia care time and low cost [9]. However, there is no recommendation for the standardized dose of botulinum toxin based on deviation angle currently. In addition, the recurrence rate of the strabismus after botulinum toxin injection is high, requiring reinjection [10]. These disadvantages limit the widespread use of botulinum toxin in the treatment of strabismus.

The prism adaptation test, which was popularized by Jampolsky in 1971, has become a possible solution for correcting acquired esotropia more accurately and successfully by revealing the maximum angle of deviation that may otherwise be masked [11, 12]. Previous studies have showed that prism correction could improve the success rate of strabismus surgery for patients with esotropia [11, 13]. Therefore, surgical treatment or preoperative prism correction is often used in treatment of AACE currently. However, it is unknown whether there is a difference between the two therapies and which treatment is better for treatment of AACE. In addition, there are few reports about the changes of binocular vision function in patients with AACE after preoperative prism correction. In this study, we aimed to compare the therapeutic effects of surgery following prism adaptation test versus surgery alone in AACE, and to provide a basis for the treatment of AACE.

\section{Methods}

\section{Patients}

Between January 2011 and September 2018, a total of 46 patients with AACE treated with surgery following prism adaptation test (combination group) vs. surgery alone (surgery group) at our hospital were included in this retrospective study. Ethics approval was obtained from the Institutional Review Board of Jinan Second People's Hospital and informed consent was obtained from each participant and their guardians.

The inclusion criteria were: (1) patients with a diagnosis of AACE; (2) patients with sudden-onset esotropia with diplopia (same deviation in all gaze direction); (3) patients with the corrected visual acuity not less than 20/20 in both eyes; (4) patients with duration of more than 2 months from onset to treatment.

The exclusion criteria were: (1) patients with other eye diseases, such as strabismus and amblyopia; (2) history of eye trauma, medication and surgery; (3) presence of systemic diseases (such as diabetes, myasthenia gravis, etc); (4) history of brain tumor or neurological disease.

\section{Ophthalmological examination}

All patients underwent routine ophthalmologic examinations (refraction, visual acuity, outer eye, anterior segment, fundus), head computed tomography (CT) or magnetic resonance imaging (MRI). As descripted previously, AACE was classified into Swan type, Burian-Franceschetti type and Bielschowsky type [2, 3]. The accommodative convergence/accommodation $(\mathrm{AC} / \mathrm{A})$ ratio was measured with the gradient method preoperatively to check for accommodative esotropia. Cycloplegic refraction was performed after administering $1 \%$ atropine ointment in patients $<9$ years and $1 \%$ compound tropicamide eye drops for those $\geq 9$ years old. The three grades of binocular visual function including simultaneous perception, fusion and stereopsis were measured by synoptophore (TSJ-IV-A, Photoelectric Instrument Co., Ltd. Changchun, China). The distant $(6 \mathrm{~m})$ and near $(33 \mathrm{~cm})$ deviation angles was measured by prism and alternating cover test. Near stereoacuity was measured using the Titmus test (Stereo Optical, Chicago, IL) at the standard viewing distance of $40 \mathrm{~cm}$ with full correction [14]. Patients were asked to catch the wings of the fly, and then proceed to the row of animals, followed by graded circle test. Patients were asked to point to animal or circle or push the circle which seemed to float up. Following the correct response, patients were shown the next level of targets and the near stereoacuity values were recorded. Therefore, the criterion for recording was successive correct responses at a given disparity level (ranges from $800^{\prime \prime}$ to 40 ").

\section{Therapeutic methods}

During calculation of prism strength, the prisms were equally divided over the left and right eyes in a trialframe to correct for the esotropia. The combination group was then given prism correction using Fresnel press-on prisms mounted base out over the entire lens on the patient's spectacle correction within 1 week to 3 months after the onset. The initial prism power was based on amount of near esodeviation while fixating on an adaptive target.

All patients were observed until 6 months after the onset, and surgery could only be performed after the degree of strabismus had stabilized. When the angle of deviation was larger at distance than at near ( $\geq 10 \mathrm{PD})$, it was considered to be divergence insufficiency type of esotropia. In contrast, when the angle of deviation was larger at near than at distance ( $\geq 10 \mathrm{PD})$, it was considered to be convergence excess type of esotropia. Basic type of esotropia was defined as a $<10-\mathrm{PD}$ difference between near and distance deviations. In patients with basic type and convergence excess type of esotropia, our operation of choice was unilateral or bilateral medial 
rectus recession. In patients with divergence insufficiency type of esotropia, we preferred medial rectus recession and lateral rectus resection. The surgery was performed under general anesthesia in patients $<14$ years and local anesthesia for those $\geq 14$ years old. The prisms were discontinued after surgery.

\section{Observational items}

The mean preoperative prism correction time was $6.5 \pm$ 1.8 months (range, 3-20 months). Three grades of binocular visual function, near stereoacuity, distant and near deviation angles and complications were measured during the follow-up period (12 months). Success was defined as postoperative total horizontal deviation of 10 PD or less. Near stereoacuity $\leq 60$ " was the central stereopsis, 80 "-800" was peripheral stereopsis, and $\geq 800$ " was stereo blindness.

\section{Statistical analysis}

Statistical analysis was performed by IBM SPSS Statistics Version 20.0 (IBM Corp., Armonk, NY, USA). Numerical data were expressed as means \pm standard deviations (SD) and were compared using Student's t-test. Categorica data were expressed as number and percentage and were compared using $X^{2}$ test. Statistical significance was set at $p<0.05$.

\section{Results}

\section{Baseline characteristics}

A total of 46 patients diagnosed with AACE were retrospectively analysed in this study. Among them, 26 patients including $14(53.85 \%)$ males and 12 (46.15\%) females with the mean age of $19.00 \pm 11.16$ years (range, 4-50 years) underwent surgery following prism adaptation test (combination group), and another 20 patients including 11 (55.00\%) males and 9 (45.00\%) females with the mean age of $18.80 \pm 9.79$ years (range, 3-45 years) underwent surgery only (surgery group). The baseline characteristics of included subjects are listed in Table 1 .
The two groups were generally well balanced for age, sex, time from onset to treatment, refraction and type of AACE (all $p>0.05$, Table 1).

In the combination group, 14 patients underwent two muscle surgery and 12 patients underwent single muscle surgery. In the surgery group, 12 patients underwent two muscle surgery and 8 patients underwent single muscle surgery.

\section{Clinical evaluation outcomes}

At post-treatment 12 months, the success rate was 96.15\% (25/26) in the combination group and $90.00 \%$ $(18 / 20)$ in the surgery group, and no significant difference between two groups $(p>0.05)$.

The distant and near deviation angles 12 months postoperatively in two groups were significantly lower than that before surgery (all $p<0.05$ ), suggesting the effectiveness of these two treatment methods (Table 2). However, there were no significant differences in the distant and near deviation angles between combination group and surgery group postoperatively.

The three grades of binocular visual function (Table 2) results showed that the numbers of patients with simultaneous perception and stereopsis 12 months postoperatively in two groups were significantly higher than that before operation (all $p<0.05$ ). In addition, changes in fusion were also observed after post-treatment 12 months, but only the combination group reached statistical significance $(p<0.05)$. Moreover, the numbers of patients with stereopsis in the combination group were significantly higher than that in the surgery group postoperatively $(p<0.05)$. These results indicated surgery following prism adaptation test had better treatment benefits than surgery alone in improving visual function.

As shown in Table 2, the numbers of patients with stereo blindness were all significantly reduced 12 months postoperatively in two groups $(p<0.05)$, but no statistical difference was observed between the two groups. In addition, the numbers of patients with central stereopsis

Table 1 Baselines characteristics of included patients

\begin{tabular}{llll}
\hline Characteristics & Combination group $(n=26)$ & Surgery group $(n=20)$ & $p$ value \\
\hline Age (years), Mean \pm SD/range & $19.00 \pm 11.16(4-50)$ & $18.80 \pm 9.79(3-45)$ & $11(55.00) / 9(45.00)$ \\
Gender (no, \%), M/F & $14(53.85) / 12(46.15)$ & $8.95 \pm 3.66$ & \\
Time from onset to treatment (mo), Mean \pm SD & $9.00 \pm 3.14$ & $2.29 \pm 3.09$ \\
Refraction (D), Mean \pm SD & & $2.08 \pm 3.05$ & 0.983 \\
$\quad$ Right & $2.02 \pm 3.29$ & & \\
$\quad$ Left & $1.86 \pm 3.14$ & 10 & 0.787 \\
Type of AACE & 11 & 13 & 0.813 \\
$\quad$ Burian-Franceschetti & 12 &
\end{tabular}

$M$ male; $F$ female; no number; $S D$ standard deviations; $D$ diopter; mo months 
Table 2 The deviation angles and visual function in two groups preoperatively and postoperatively

\begin{tabular}{|c|c|c|c|c|}
\hline \multirow[t]{2}{*}{ Parameter } & \multicolumn{2}{|c|}{ Combination group $(n=26)$} & \multicolumn{2}{|c|}{ Surgery group $(n=20)$} \\
\hline & Preoperative & Postoperative & Preoperative & Postoperative \\
\hline \multicolumn{5}{|l|}{ Deviation angles, Mean \pm SD } \\
\hline Distant & $39.62 \pm 12.48$ & $2.92 \pm 2.15^{\mathrm{a}}$ & $40.05 \pm 8.72$ & $4.00 \pm 2.51^{\mathrm{a}}$ \\
\hline Near & $37.88 \pm 11.06$ & $-0.27 \pm 2.52^{\mathrm{a}}$ & $39.00 \pm 9.54$ & $0.50 \pm 2.26^{a}$ \\
\hline \multicolumn{5}{|l|}{ Visual function, no (\%) } \\
\hline Simultaneous perception & $16(61.54)$ & $24(92.31)^{\mathrm{a}}$ & $12(60.00)$ & $18(90.00)^{a}$ \\
\hline Fusion & $10(38.46)$ & $21(80.77)^{a}$ & $6(30.00)$ & $12(60.00)$ \\
\hline Stereopsis & $5(19.23)$ & $20(76.92)^{a}$ & $3(15.00)$ & $9(45.00)^{\mathrm{ab}}$ \\
\hline \multicolumn{5}{|l|}{ Near stereoacuity, no (\%) } \\
\hline Central stereopsis & $5(19.23)$ & $22(84.62)^{a}$ & $3(15.00)$ & $11(55.00)^{\mathrm{ab}}$ \\
\hline Peripheral stereopsis & $13(50.00)$ & $24(92.31)^{a}$ & $8(40.00)$ & $17(85.00)^{\mathrm{a}}$ \\
\hline Stereo blindness & $13(50.00)$ & $2(7.69)^{a}$ & $12(60.00)$ & $3(15.00)^{\mathrm{a}}$ \\
\hline
\end{tabular}

${ }^{\mathrm{a}}$ vs. preoperative, $p<0.05 ;{ }^{\mathrm{b}}$ vs. combination group, $p<0.05$; no, number; SD, standard deviations

and peripheral stereopsis 12 months postoperatively in two groups were significantly higher than that before operation (all $p<0.05$ ). More importantly, the numbers of patients with central stereopsis in the combination group were significantly higher than that in the surgery group postoperatively $(p<0.05$, Table 2$)$. This suggested that surgery following prism adaptation test had better treatment benefits than surgery alone in improving near stereoacuity.

\section{Recurrence and complications}

At post-treatment 12 months, one (3.85\%) case recurred in the combination group and three $(15.00 \%)$ cases in the surgery group $(p>0.05)$. No complications such as scleral perforation, anterior segment ischemic syndrome, muscle slippage, muscle hematoma, subconjunctival cysts or granulation hyperplasia occurred in either group.

\section{Discussion}

AACE is an unusual presentation of esotropia that occurs in adults and older children [15]. At present, AACE is mostly treated by preoperative prism correction, surgery or botulinum toxin injection [16]. Wan et al. found that botulinum toxin was at least as effective as standard incisional strabismus surgery in the treatment of AACE at 6 months [5]. Velez et al. evaluated the efficacy of preoperative prism adaptation for a longer follow-up period in subjects with acquired esotropia, and found that patients who underwent prism adaptation maintained better motor alignment than those who not underwent prism adaptation over a long-term follow-up period (> 12 months) [17]. However, there was no existing study directly comparing the therapeutic effects of surgery following prism adaptation test versus surgery alone in AACE. In this study, we aimed to compare the therapeutic effects of surgery following prism adaptation test versus surgery alone in AACE.

The preoperative prism adaptation test has been used to determine the target angle for surgical correction and decrease the risk of undercorrection or overcorrection in patients with acquired esotropia undergoing surgical correction [18]. Previous studies have shown that preoperative prism adaptation could improve the success rate of strabismus surgery for patients with esotropia $[11,13]$. In the present study, we found that the success rate was $96.15 \%$ in the combination group and $90.00 \%$ in the surgery group. This is consistent with previous studies. Repka et al. found that success rate of patients with acquired esotropia was $90.0 \%$ after preoperative prism adaptation $[19,20]$. In addition, Lang et al. reported that the success rate of patients with AACE was $81.3 \%$ postoperatively [6]. Moreover, we found that postoperative distant and near deviation angles in two groups were significantly lower than that before operation. However, there were no significant differences in the distant and near deviation angles between two groups postoperatively. These results indicated that surgery following prism adaptation test was comparable to surgery alone in success rate and deviation angle.

Campos et al. reported that patients with Bielschonsky type AACE had a tendency to continuous binocular convergence and relapse after surgery [21]. In this study, we found that one case recurred 12 months postoperatively in the combination group and three cases in the surgery group. Consistent with previous study, all patients who relapsed were Bielschonsky type AACE. In addition, we found that the recurrence rate in the combination group was obviously lower than that in the surgery group (3.85\% vs. $15.00 \%)$, but no significant difference between the two groups $(p>0.05)$. The possible reason was that the number of samples in this experiment was small and 
the follow-up time was short and requires further research.

In the present study, we also found that $84.62 \%$ cases developed near stereoacuity $\leq 60^{\prime \prime}$ in the combination group, and $55.00 \%$ cases developed near stereoacuity $\leq 60$ " in the surgery group postoperatively. Spierer et al. found that stereoacuity was $40^{\prime \prime}$ in all adult patients after surgery [22], which was different from our reports. It may be related to the binocular visual function of adult patients had developed normally before the onset of esotropia [23]. Therefore, it could recover after strabismus surgery. In the present study, we also found that the three grades of binocular visual function (simultaneous perception, fusion and stereopsis) postoperatively in two groups were higher than that before operation. Otherwise, the stereopsis and near stereoacuity in the combination group were better than that in the surgery group postoperatively, which indicated that preoperative prism correction for patients with AACE was very important for the maintenance and recovery of binocular visual function.

There were several limitations in the present study. Firstly, this study was a retrospective study conducted at a single institute which had certain limitations in clinical application. Secondly, the number of patients included in this study was small. Thirdly, it was necessary to have a longer follow-up in the surgery following prism adaptation test group to evaluate further deterioration, especially for patients with high degree of strabismus. Fourthly, the decision of whether to proceed with prism correction plus surgery or single surgery as the primary treatment was based on patient selection and physician preference.

\section{Conclusions}

Both approaches had therapeutic benefit in AACE. Surgery following prism adaptation test had better treatment benefits than surgery alone in improving binocular function and reducing recurrence rate.

\section{Abbreviations}

AACE: Acute acquired comitant esotropia; CT: Computed tomography; MRI: Magnetic resonance imaging; SD: Standard deviations

\section{Acknowledgments}

None.

\section{Authors' contributions}

P.Z. and J.Y. conceived the project and designed the experiments. P.Z., Y.Z., and L.G. performed the experiments and analyzed the data. P.Z. and J.Y. wrote the paper. All authors had read and approved the manuscript.

\section{Funding}

None.

Availability of data and materials

Data is obtained with the permission of the corresponding author.
Ethics approval and consent to participate

Ethics approval is obtained from the Institutional Review Board of Jinan Second People's Hospital.

\section{Consent for publication}

Not applicable.

\section{Competing interests}

The authors declare that they have no conflict of interest.

Received: 26 March 2020 Accepted: 20 July 2020

Published online: 23 July 2020

References

1. Fu T, Wang J, Levin M, Xi P, Li D, Li J. Clinical features of acute acquired comitant esotropia in the Chinese populations. Medicine. 2017;96(46):e8528.

2. Lee HJ, Kim SJ. Clinical characteristics and surgical outcomes of adults with acute acquired comitant esotropia. Jpn J Ophthalmol. 2019;63(6): 483-9.

3. Cai C, Dai H, Shen Y. Clinical characteristics and surgical outcomes of acute acquired Comitant Esotropia. BMC Ophthalmol. 2019;19(1): 173.

4. Gilbert AL, Koo EB, Heidary G. Evaluation and management of acute acquired comitant esotropia in children. In: Seminars in ophthalmology: 2017: Taylor \& Francis; 2017. p. 8-13.

5. Wan MJ, Mantagos IS, Shah AS, Kazlas M, Hunter DG. Comparison of botulinum toxin with surgery for the treatment of acute-onset comitant esotropia in children. Am J Ophthalmol. 2017;176:33-9.

6. L-j L, Zhu Y, Li Z-G, Zheng G-Y, Peng H-Y, Rong J-B, Xu L-M. Comparison of botulinum toxin with surgery for the treatment of acute acquired comitant esotropia and its clinical characteristics. Sci Rep. 2019;9(1):1-6.

7. Stangler-Zuschrott E. Prism treatment of strabismus in childhood-an overview of forty years. Jpn J Med. 2019:2:2.

8. Erkan-Turan K, Taylan-Şekeroğlu H, Ağın A, Sanaç AŞ. Why and when to prefer botulinum toxin injection in childhood strabismus? Turk J Pediatr. 2017;59(6):684-7.

9. Gómez de Liaño R. The Use of Botulinum Toxin in Strabismus Treatment. J Binocul Vis Ocul Motil. 2019;69(2):51-60.

10. Mahan M, Engel JM. The resurgence of botulinum toxin injection for strabismus in children. Curr Opin Ophthalmol. 2017:28(5):460-4.

11. Ohtsuki H, Hasebe S, Tadokoro Y, Kishimoto F, Watanabe S, Okano M. Preoperative prism correction in patients with acquired esotropia. Graefes Arch Clin Exp Ophthalmol. 1993;231(2):71-5.

12. Kutschke PJ, Keech RV. Surgical outcome after prism adaptation for esotropia with a distance-near disparity. J Am Assoc Pediatr Ophthalmol Strabismus. 2001:5(3):189-92.

13. Giangiacomo J. Efficacy of prism adaptation in the surgical management of acquired esotropia. Arch Ophthalmol. 1991;109(6):765.

14. Moganeswari D, Thomas J, Srinivasan K, Jacob GP. Test re-test reliability and validity of different visual acuity and stereoacuity charts used in preschool children. J Clin Diagn Res. 2015:9(11):NC01.

15. Lee HS, Park SW, Heo H. Acute acquired comitant esotropia related to excessive smartphone use. BMC Ophthalmol. 2016;16(1):37.

16. Couser NL, Lambert SR. Botulinum toxin a treatment of consecutive esotropia in children. Strabismus. 2012;20(4):158-61.

17. Velez FG, Rosenbaum AL. Preoperative prism adaptation for acquired esotropia: long-term results. J Am Assoc Pediatr Ophthalmol Strabismus. 2002;6(3):168-73.

18. Ela-Dalman N, Velez G, Thacker N, Britt MT, Velez FG. Maximum motor fusion combined with one-hour preoperative prism adaptation test in patients with acquired esotropia. J Am Assoc Pediatr Ophthalmol Strabismus. 2006:10(6):561-4.

19. Repka MX, Connett JE, Scott WE, Group PASR. The one-year surgical outcome after prism adaptation for the management of acquired esotropia. Ophthalmology. 1996;103(6):922-8.

20. Greenwald MJ. Prism adaptation study. Ophthalmology. 1997;104(11): 1725 . 
21. Savino G, Colucci D, Dickmann A. Acute onset concomitant esotropia: sensorial evaluation, prism adaptation test, and surgery planning. J Pediatr Ophthalmol Strabismus. 2005;42(6):342.

22. Spierer A. Acute concomitant esotropia of adulthood. Ophthalmology. 2003; 110(5):1053-6.

23. Mills MD, Coats DK, Donahue SP, Wheeler DT. Strabismus surgery for adults: a report by the American Academy of ophthalmology. Ophthalmology. 2004;111(6):1255-62.

\section{Publisher's Note}

Springer Nature remains neutral with regard to jurisdictional claims in published maps and institutional affiliations.

Ready to submit your research? Choose BMC and benefit from:

- fast, convenient online submission

- thorough peer review by experienced researchers in your field

- rapid publication on acceptance

- support for research data, including large and complex data types

- gold Open Access which fosters wider collaboration and increased citations

- maximum visibility for your research: over $100 \mathrm{M}$ website views per year

At $B M C$, research is always in progress.

Learn more biomedcentral.com/submissions 